\title{
Research on the design of public charging infrastructure for electric vehicles
}

\author{
LI Chunliang ${ }^{1, \text { a }}$, WANG Jinling ${ }^{2}$, WU Guo liang ${ }^{3}$, WANG Jiaying ${ }^{4}$, LIU He $^{5}$ \\ 1,2,4.5 Electric power science research institute of jilin electric power Co., Ltd. , jilin,130021,China \\ ${ }^{3}$ Electric power science research institute of hei long jiang electric power Co., Ltd., \\ Harbin,150000,China \\ aemail: lichunliang@163.com
}

Keywords: Electric vehicles; charging technology; research status; development trend

\begin{abstract}
On the domestic and foreign electric vehicles, electric vehicle charging technology and planning layout and other aspects of the status quo, and the need for electric vehicle charging analysis. Introduced the domestic and foreign electric vehicle charging facilities, the future prospects for the development of electric vehicles in China were preliminary research, put forward actively promote electric vehicle charging infrastructure construction should be is the power grid enterprise's bounden responsibility and future development opportunities.
\end{abstract}

\section{Introduction}

Electric vehicle is in whole or in part by electricity can drive motor as a dynamic system of automobile, in accordance with the current technology development direction or vehicle driving principle, divided into three types: pure electric vehicles, hybrid vehicles and fuel cell electric vehicle. In recent years, China's electric vehicle industry has achieved rapid development, to overcome a series of key technical problems, in some areas has been achieved with Japan and the u.s.. At present, China's development of electric vehicles has a large consumer market, low manufacturing cost, technology to achieve a partial breakthrough, the four major advantages of resource protection capability. Under the dual stimulation technology breakthrough and policy support, electric vehicle in our country has been in critical point to detonate market expected future two years of electric vehicle market scale and production scale will expand rapidly, electric vehicles will enter a rapid growth period. Electric vehicle charging facilities is an important part of the electric vehicle industry chain. In the development of electric vehicle industry, it should also fully consider the development of charging facilities[1].

\section{The basic way of charging electric vehicles}

At present, there are three kinds of charging methods for electric vehicles, which are slow charge, fast charge and fast charge:

(1) slow charging mode. Slow charge general with a small alternating current for charging, charging time is usually 6 to $10 \mathrm{~h}$, slow charging mode generally use the evening for charging, charging can be the evening low price, helps to reduce the cost of charging. But they are difficult to satisfy user emergency or long distance travel demand. Slow charge generally use single-phase 220V/16A AC power supply, through the car charger to charge the electric car, car charger can use GB three sockets, the basic does not exist the problem of the interface standard. In general, the electric vehicle is carried through the charging pile.

(2) fast charge mode. Fast charge, also known as emergency charging, with large DC current within $20 \mathrm{~min}$ to $1 \mathrm{~h}$, for electric vehicles provides short service charge, fast charge mode can solve the problem of the mileage of electric energy supply problems, but the battery life influence, because current is bigger, of technology and safety requirements are higher. Fast charge is characterized by high voltage, large current, charging time is short (about $1 \mathrm{~h}$ ). The charging way of charging socket pin definitions, voltage, current value, control protocol etc. were no national 
standards, there is no international standard, has been put into use the charger and batteries for electric cars charging socket were by the manufacturers of custom, all the countries in the world are in actively compete for the standard formulation right, the electric car manufacturers have preemptive launch, to seize the market, increase market share, tried to convince the majority of the charging station to adopt the charging equipment, thereby becoming the de facto standard. Fast charge mode is mainly carried out in the charging station[2].

(3) fast changing mode. Quick change is through the direct replacement of car batteries, the way to add power, power and fuel vehicles for a similar time, about 10 to $5 \mathrm{~min}$. Quick change the most convenient way, but the need for electric vehicles and car batteries to achieve standardization, and fast changing process requires professional personnel to operate. Quick change can be in the charging station can also be completed in a dedicated battery replacement station. The advantages of electric vehicle batteries without on-site charging, replace battery time shorter, but requires cell shape, capacity and other parameters of the complete reunification. At the same time, also called the structural design of the electric vehicle can satisfy the battery replacement convenient, fast.

\section{Development of electric vehicle charging facilities in foreign countries}

At present, the United States, Japan, Israel, France, the United Kingdom and other countries have begun to build their own electric car charging facilities, mainly in charge of pile based.

(1) the United States

The vast territory of the United States, and the strong independence of the states in the electric car and its charging facilities are different states have different, California, Virginia and other places have carried out the construction of charging facilities. The California building efforts, by the beautiful space project company in Northern California San Francisco, Oakland and San Jose City Government to jointly build and will be in 2012 in the city of all residential areas, commercial buildings, parking lots and government buildings to install charging pile, to convenient electric car drivers at any time for the car charging. The company will build a battery replacement station in the above areas, to facilitate long-distance drivers to replace batteries at any time, the total investment of the project plans to reach $\$ 1$ billion. In addition, the United States first solar energy company (SolarCity) in California on the 101 highway built 5 charging stations. Each charging station can provide $240 \mathrm{~A}, 70 \mathrm{~V}$ fast charging service, can be in $3.5 \mathrm{~h}$ for the Tesla pure electric car full of electricity.

(2) Japan

As of 2009, Japan has more than 100 charging stations, of which $60 \%$ are concentrated in the Tokyo area. The Japanese government said, as the popularity of electric vehicles, charging stations will be built in more than three years. Japan's Tokyo Electric Power Company will take the lead in foundation construction, Tokyo in 2010 will be the first built more than 200 charging stations, is expected to after three years will be increased to more than 1000, in Tokyo charging pile is more popular, building road can be seen everywhere. Kanagawa County, near Tokyo, plans to drive at least 3000 electric vehicles on the road in 5 years. The county has promised to provide 150 fast charging stations. Japan's central government to support this technology, the city will be selected to carry out electric vehicle charging project. The project will be involved in the payment of car parking, supermarkets and restaurant chains to install power outlets for drivers to use free of charge.

(3) the United Kingdom

In the UK, London has 60 free car charging, power driven car can be very conveniently in the nearby residential and office building next to or on a busy street find charging pile, enjoy excluding charges and parking service, a year only 75 pounds of tube processing fees[3].

(4) France

In France, the power companies in the city to build a lot of charging stations for electric vehicles to use, while the electric car can be charged at home. As of 2008, the whole of France has more than 1 vehicles of various types of electric vehicles, 200 public charging stations, electric vehicle demonstration applications focused on municipal, postal, bus, power, sanitation and other public utilities. 
(5) Israel

On January 21, 2008, Renault - Nissan Motor Company to join the project better place and the Israeli government signed a memorandum of understanding, the decision to carry out cooperation in the next three years, to jointly promote the application of pure electric vehicle market. According to the cooperation agreement, the Israeli government will be responsible for the formulation of preferential tax policies for consumers, Renault will be responsible for the supply of electric vehicles, and project better place company is responsible for construction within the country of Israel charging station infrastructure. Project better place company plans within the next three years the construction of large-scale battery charging infrastructure network; at the same time, electric cars will be equipped with can real-time display the remaining battery power and charging station location of on-board computer system. Companies plan to promote a business model, the model will be distinguished from the car and the battery that customers do not have a battery, only the rental battery. The company will set up a charging network and a large number of exchange service stations throughout the country, so that customers can easily charge fast, or replace the battery at the switching service station.

Israel's charging station infrastructure mode can be summarized as government concessions, the company's operation, the company owned by the company, rent for convenient".

\section{Development status of charging facilities for electric vehicles in China}

Charging infrastructure development plan, from 2010 to national electric vehicle infrastructure planning began to appear in the ultra fast development, national grid, China Southern Power Grid, PetroChina, Sinopec, CNOOC and other large state-owned group have released electric vehicle charging facilities planning or construction intentions[4].

January 27, 2010, the social responsibility report released by the China State Grid Corp, will be in 2010 by the end of in 27 areas to build 75 electric vehicle charging stations and 6029 charging piles pilot.

Southern Power Grid Corp will be listed as the first batch of new energy pilot cities in Shenzhen. According to the Shenzhen city planning, by 2012, Shenzhen will build all kinds of new energy vehicle charging station 12 750, the bus rapid transit, slow charging station, 25, official car charging pile 2 500, the social public slow charging pile 1 million, social public fast charging station 200 .

Petroleum and petrochemical industry is not far behind, have joined the construction of charging stations. CNOOC and China Putian joint venture -- Putian CNOOC new energy Co., Ltd. is with the Zotye auto signed a strategic cooperation agreement, plans in early 2010 in two or more capital city started construction of a pure electric vehicle charging station network. Sinopec Group and the Beijing municipal government to jointly promote the construction of pure electric vehicle charging station infrastructure, the main use of Sinopec is now a large area of gas, filling stations converted into a gas charging service station. Sinopec's gas charging service station will be the first to extend to the city of Beijing, and then extended to Tianjin, Hebei, and even greater range.

From the point of view of commercial operation, the battery model is a new energy logistics mode. Change the battery mode is conducive to the size of the battery production enterprises, standardized production, is conducive to the large-scale procurement and intensive management of energy supply enterprises, will significantly reduce the total operating costs. Energy supply enterprise as a relatively independent among operators, is conducive to the implementation of more for support and preferential policies, such as price policy, to buy Battery subsidy policy, easy to establish a clear financial profitability models, than simply providing charging service can obtain a higher return on investment, with a broader space for development. In addition, this model of grid security, economic operation is also very beneficial and concentrated charging for unified scheduling, management and monitoring, to maximize play peak clipping fill valley, increase the rate of power system load, minimize harmonic pollution to grid adverse effects, is conducive to the optimization of the power grid safe and stable operation and power resources and utilization.

Battery replacement station pattern theory is a kind of ideal business model, domestic individual cities have carried out a pilot operation, but in the short term, large-scale promotion of this model, 
there are some difficulties, mainly reflected in the following three aspects: management, our country in the electric car industry in the early stage of the development, battery technology is not yet mature, a variety of battery performance, quality gap, uniform standard battery difficulty very large. This is not only a battery of standardized, but also related to the standardization of electric vehicles, is a huge systematic project, involving steam car factory, battery manufacturers, replacement station operators and other interests. Two is the technical aspects, in order to ensure that the battery can be replaced, all batteries must have good consistency. Not only to a unified interface standard battery, but also a unified cell dimensions, specifications, capacity and performance, in the case of the current domestic battery manufacturers conflicts, unified all battery manufacturers in the production of battery consistency problem, it is difficult to achieve in the short term. Three is the battery circulation, the battery replacement process will be the difference between the old and new, residual energy, it will bring about the problem of how to measure the battery replacement, billing.

In the short term, in the primary stage of the development of electric vehicles, the construction of a number of fully functional charging station is very necessary, can produce a good demonstration effect and advertising effect, promote the popularity of electric vehicles as soon as possible. However, if the electric vehicle mass popularity, relying on the charging station is unable to solve the problem of charging, but also consume too much of the land resources. Public charging stations should be located in the main to meet the emergency needs of a variety of social vehicles, in order to provide fast charging service.

From the perspective of the use of convenience and conservation of resources, the future in our country to occupy the dominant position of the conventional charging mode should be slow charge, parking and roadside charging piles will become the dominant charging facilities. With the rapid growth of the number of electric vehicles, should be formed to "charging pile, charging stations, supplemented by" the charging network, charging piles used for conventional slow charge, charging stations to meet the needs of emergency fast charge. Therefore, in our country at present, we should strengthen the charging pile planning, construction, operation and other issues related to research and accelerate the charging pile layout and construction.

From the business point of view, and the replacement of the battery stations belonging to the new logistics mode of energy, is conducive to the battery production enterprises of large-scale, standardized production, is conducive to the energy supply of the enterprise scale purchasing and intensive management, the theory is a kind of ideal business model. However, this model is currently in the management, technical and commercial difficulties, it is difficult to large-scale promotion in the short term. When China's electric car industry development to mature stage, and the replacement of the battery model will likely become more mature, more efficient business model, and in the near future in the individual with the conditions of the city to carry out the battery replacement station mode of pilot[5].

In short, the battery replacement station mode to become a mature business model, there is still a long way to go.

\section{Conclusion}

(1) to actively promote the construction of charging facilities for electric vehicles is the incumbent social responsibility of power grid enterprises

Realizing the industrialization of electric vehicles is the strategic choice for China to safeguard national energy security, to achieve energy saving and emission reduction, and to revitalize the automobile industry. Construction of electric vehicle charging network is the prerequisite for the realization of industrialization, electric vehicles as a strategic emerging industries and pillar industries of the future, is about to enter a period of rapid growth. At present, the relative lag of electric vehicle charging facilities construction has become a bottleneck restricting the development of electric vehicles, accelerating the construction of charging facilities without delay. In the early days of the popularity of electric vehicles, the construction of charging facilities in the short-term economic benefits is not obvious, the general social funds are not willing to invest in the 
construction of charging facilities. Power grid enterprises as a large state-owned energy enterprises, have the obligation to assume their social responsibility, actively promote all kinds of charging facilities to support and promote the development of emerging industries, and make due contribution for our country to achieve the economic growth mode transformation.

(2) power grid enterprises in the field of charging facilities have obvious advantages

Compared with other charging facilities potential investors, power grid enterprises technical field of the construction of the charging station has more advantages, charging stations should use the transformer, voltage grade, how to and distribution network coordinated optimization, power grid enterprises know best, it got all the familiar road. In fact, because all of the charging facilities must rely on the existing power supply network to build, so the power grid enterprises to complete the city charging station, parking lot and roadside charging pile construction planning is the most appropriate.

(3) electric vehicle industrialization also provides a historical opportunity to accelerate the development of power grid

Electric vehicle industrialization also brings a good opportunity for the development of power industry and power grid enterprises. First, the popularity of electric vehicles can change the structure of China's energy consumption, and significantly improve the proportion of energy consumption in the energy consumption, is conducive to improve the sale of electricity, expand the electricity market. Secondly, the power grid enterprises to build an electric vehicle charging facilities, explore innovative business model, you can expand the service sector Power Grid Corp, is conducive to the extension of the Power Grid Corp to downstream industries. Again, with the development of electric vehicle battery technology, electric vehicles will become the future of mobile storage equipment. Therefore, building electric car charging facilities for power grid companies to promote the construction of strong smart grid also has a positive significance.

Anyway, and actively promote the electric vehicle charging infrastructure construction is not only conducive to the development of the national economy, but also conducive to the development of the power system, so power grid company should actively assume their social responsibility, continue to accelerate the electric vehicle charging infrastructure construction.

\section{References}

[1] Zhang Wenliang, Wu Bin, Li Wufeng et al. Study on the development direction and energy supply mode of China's pure electric vehicles. [J], 2009,33 (4): 1-5.

[2] Ouyang Minggao, China's energy saving and new energy vehicle development strategy and countermeasures. Automotive engineering [J], 2006,28 (4): 317-321.

[3] Wu Bin; Zhang Wenliang; Li Wufeng; the development direction of China's pure electric vehicle and energy supply mode. The grid technology [J], 2009 (04).

[4] Wang Xuhua, Li Wei, China's electric vehicle charging facilities development trends and countermeasures. Power grid technology [J], 2013,31 (5): 32-45.

[5] Li Weihua, Zhang Hua, the current situation and problems of the development of electric vehicles in China and the infrastructure construction planning. Automotive engineering [J], 2014,22, (5): 23-25. 